\title{
XRCC1 Arg399GIn and RAD51 5'UTR G135C polymorphisms and their outcome in tumor aggressiveness and survival of Portuguese breast cancer patients
}

\author{
Sandra Costa $\cdot$ Daniela Pinto $\cdot$ Deolinda Pereira $\cdot$ \\ Helena Rodrigues · Jorge Cameselle-Teijeiro • \\ Rui Medeiros · Fernando Schmitt
}

Received: 23 May 2007/ Accepted: 30 May 2007/Published online: 7 July 2007

(C) Springer Science+Business Media B.V. 2007

Breast cancer (BC) is the most common type of cancer in female, including Portugal, where this disease presents the highest incidence and mortality rates [1]. BC risk factors, like prolonged exposure to estrogen and/or ionizing radiation, BRCA1, BRCA2, TP53, ATM and CHEK2 mutations $[2,3]$, are related with an increased chance of DNA damage, acting as initiators of cellular alterations. DNA repair pathways are critical processes in order to maintain genome integrity. Therefore, genetic polymorphisms in DNA repair genes are common events [4]. We previously showed correlations of some of these genetic variations, as

S. Costa

ICVS, Life and Health Sciences Research Institute, Health

Science School, Minho University, 4710-057, Braga, Portugal

D. Pinto

Molecular Oncology Unit, Portuguese Institute of Oncology,

4200-072, Porto, Portugal

D. Pereira $\cdot$ H. Rodrigues

Medical Oncology Department, Portuguese Institute of

Oncology, 4200-072, Porto, Portugal

J. Cameselle-Teijeiro

Hospital Xeral-Cíes, Vigo, Spain

\section{R. Medeiros}

Molecular Oncology Unit, Portuguese Institute of Oncology Porto and ICBAS (Abel Salazar Institute for the Biomedical Sciences), 4099-003, Porto, Portugal

\section{F. Schmitt $(\square)$}

IPATIMUP (Institute of Molecular Pathology and Immunology of the University of Porto) and Medical Faculty of Porto University, Rua Dr. Roberto Frias s/n, 4200-465, Porto, Portugal e-mail: fschmitt@ipatimup.pt
XRCC1 Arg399Gln, RAD51 5'UTR G135C and XRCC3 Thr24lMet, with changeable BC susceptibility [5].

In the present study, we aimed to investigate the possible correlations between DNA repair polymorphisms with BC clinico-pathological phenotypes, identifying subgroups of patients according to their genetic background.

We analysed DNA from 165 BC patients, including 33 unrelated family history (FH) and 132 sporadic $\mathrm{BC}$ cases from Surgical Departments of S. João Hospital and the Oncology Portuguese Institute, at Porto. All participants provided informed consent. Patients presented a mean age of 51.01 years (standard deviation $(\mathrm{SD}) \pm 12.68$ ).

We determined XRCC1 Arg399Gln, RAD51 5"UTR G135C and XRCC3 Thr241Met genotypes by PCR-RFLP technique, as previously described [5]. Chi-square $\left(\chi^{2}\right.$ test) analysis was used to compare different variables. Logistic regression analysis was applied to calculate the adjusted $p$ value for age and $\mathrm{FH}$ in identification of subgroups of patients according to genotypes. The Kaplan-Meier method was used to estimate overall survival (OS). OS was defined as minimal 60 months follow-up, from clinical diagnosis until death or censorship (were alive at the end of the follow-up time period). Differences on OS were obtained by Log Rank test.

The correlation of the analysed DNA repair polymorphisms with some clinical-pathological features is presented in Table 1. According to our results, XRCC1 $G l n / G l n$ genotype seems to be associated with less aggressive tumors, since this genotype was correlated with well differentiated tumors $(p=0.022$ adjusted for age and $\mathrm{BC} \mathrm{FH}$, using logistic regression analysis). Deficient efficiency of the XRCC1 protein has been described in XRCC1 Gln399 variant [6, 7]. Furthermore, repair of more complex base lesions $[8,9,10]$ by base excision repair (BER) pathway can potentially convert 
Table 1 Correlation between DNA repair polymorphisms and clinical pathological parameters in Portuguese breast cancer patients

\begin{tabular}{|c|c|c|c|c|c|c|}
\hline \multirow[t]{2}{*}{ Parameters } & \multicolumn{2}{|c|}{ XRCC1 Arg399Gln } & \multicolumn{2}{|c|}{$R A D 51 G 135 C$} & \multicolumn{2}{|c|}{ XRCC3 Thr241Met } \\
\hline & $G \ln / G \ln$ & Others & $G C$ or $C C$ & $G G$ & Met/Met & Others \\
\hline \multicolumn{7}{|l|}{ Histological Type } \\
\hline Invasive ductal & $23(92.0)$ & $115(86.5)$ & $32(91.4)$ & $113(86.9)$ & $23(88.5)$ & $120(88.2)$ \\
\hline Invasive lobular & $0(0.0)$ & $3(2.3)$ & $0(0.0)$ & $3(2.3)$ & $1(3.8)$ & $2(1.5)$ \\
\hline Others & $2(8.0)$ & $15(11.3)$ & $3(8.6)$ & $14(2.3)$ & $2(7.7)$ & $14(10.3)$ \\
\hline $\mathrm{P}$ value & 0.654 & & 0.606 & & 0.665 & \\
\hline \multicolumn{7}{|c|}{ Histological Grade } \\
\hline I & $5(23.8)$ & $8(7.1)$ & $6(18.2)$ & $9(8.3)$ & $1(4.0)$ & $14(12.4)$ \\
\hline II & $6(28.6)$ & $61(54.0)$ & $21(63.6)$ & $51(47.2)$ & $11(44.0)$ & $57(50.4)$ \\
\hline III & $10(47.6)$ & $44(38.9)$ & $6(18.2)$ & $48(44.4)$ & $13(52.0)$ & $42(37.2)$ \\
\hline$P$ value & $0.021^{\mathrm{a}}$ & & $0.017^{\mathrm{b}}$ & & 0.269 & \\
\hline \multicolumn{7}{|c|}{ Axillary lymph node status } \\
\hline Negative & $10(41.7)$ & $52(40.0)$ & $12(40.0)$ & $54(41.5)$ & $8(32.0)$ & $57(43.5)$ \\
\hline Positive & $14(58.3)$ & $78(60.0)$ & $18(60.0)$ & $76(58.5)$ & $17(68.0)$ & $74(56.5)$ \\
\hline$P$ value & 0.878 & & 0.877 & & 0.285 & \\
\hline \multicolumn{7}{|c|}{ Oestrogen receptor status } \\
\hline Negative & $1(33.3)$ & $9(31.0)$ & $2(28.6)$ & 7 (25.9) & $1(33.3)$ & $8(27.6)$ \\
\hline Positive & $2(66.7)$ & $20(69.0)$ & $5(71.4)$ & $20(74.1)$ & $2(66.7)$ & $21(72.4)$ \\
\hline$P$ value & 0.935 & & 0.888 & & 0.833 & \\
\hline \multicolumn{7}{|c|}{ Survival status at last follow-up } \\
\hline Death & $3(15.0)$ & $13(12.5)$ & $2(8.3)$ & $15(14.0)$ & $1(4.0)$ & $16(15.4)$ \\
\hline Alive & $17(85.0)$ & $91(87.5)$ & $22(91.7)$ & $92(86.0)$ & $24(96.0)$ & $88(84.6)$ \\
\hline$P$ value & 0.760 & & 0.454 & & 0.131 & \\
\hline \multicolumn{7}{|c|}{ Recurrence at last follow-up } \\
\hline No & $14(77.8)$ & $74(82.2)$ & $19(86.4)$ & $74(80.4)$ & $20(87.0)$ & $72(80.0)$ \\
\hline Yes & $4(22.2)$ & $16(17.8)$ & 3 (13.6) & 18 (19.6) & $3(13.0)$ & $18(20.0)$ \\
\hline$P$ value & 0.658 & & 0.519 & & 0.444 & \\
\hline
\end{tabular}

a $p$ value $=0.022$, adjusted for age and history family of breast cancer to compare the influence of different genotypes in histological grade (I vs II/III grade), using logistic regression analysis

b $p$ value $=0.011$, adjusted for age and history family of breast cancer to compare the influence of different genotypes in histological grade (I/II vs III grade), using logistic regression analysis

non-lethal lesion into lethal double strand breaks [11, 12]. Thus, deficiency in BER, by low efficiency of XRCC1, may actually reflect a well differentiated nature of the tumor cells in less aggressive tumors, since less lethal lesions are produced.

We also observed that RAD51 C135 genotypes show a relationship with more aggressive tumors and also with a poorer OS, since we found a significant association of RAD51 C135 genotypes with moderate to poor differentiated grade ( $p=0.011$, adjusted for age and BC FH, using logistic regression analysis). Additionally, assessment of OS demonstrated that patients with RAD51 C135 genotypes (102.87 months mean OS) presented a poorer survival compared with other genotype (136.36 months mean OS) (Fig. 1). These results can be explained by the location of this polymorphism in the untranslated region, may be affecting mRNA stability and/or translation efficiency, leading to altered RAD51 protein levels [13]. Thus, RAD51, the key factor of homologous recombination process, can disturb the activity of the multi protein DNA repair complex, including BRCA1, BRCA2 and XRCC3, contributing to high levels of genetic instability [14], and as a result, being correlated with more aggressive breast tumors and poor survival.

We had previously showed XRCC1 Arg399Gln and $R A D 515^{\prime} U T R$ G135C as important polymorphism to predict breast cancer risk [5]. According to the present results, we clearly underlie the role of these same polymorphisms in the prediction of breast tumor aggressiveness and patients' survival. 


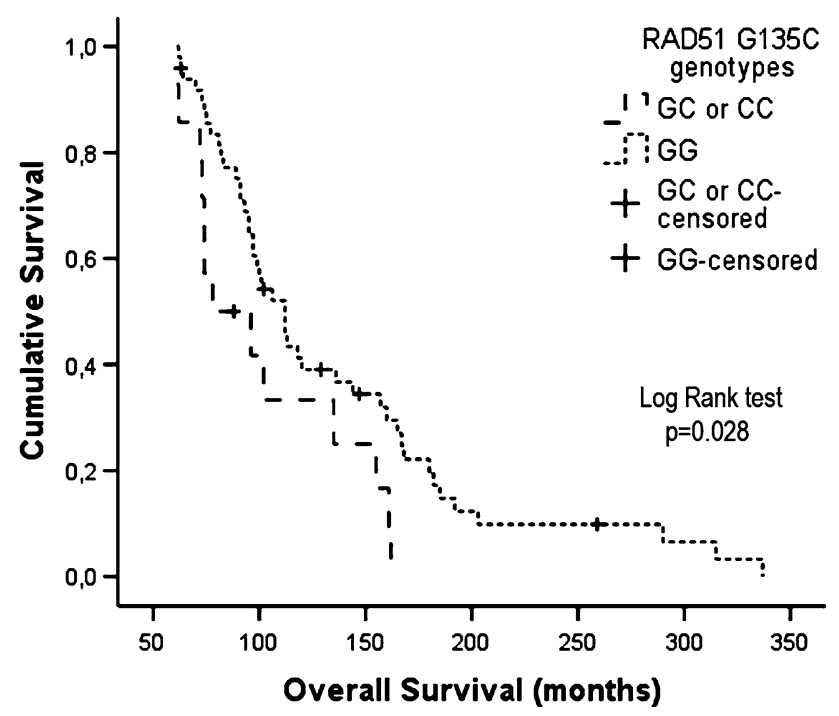

Fig. 1 Kaplan-Meier overall survival curve in breast cancer patients relating with RAD51 G135C polymorphism. Log-rank test for statistical analysis

\section{References}

1. Pinheiro PS, Tycznski JE, Bray F et al (2003) Cancer Incidence and mortality in Portugal. Eur J Cancer 39:2507-2520

2. Dumitrescu RG, Cotarla I (2005) Understanding breast cancer risk - where do we stand in 2005? J Cell Mol Med 9:208-221

3. Yager JD, Davidson NE (2006) Estrogen carcinogenesis in breast cancer. N Engl J Med 354:270-282
4. Mohrenweiser HW, Xi T, Vazquez-Matias J et al (2002) Identification of 127 amino acid substitution variants in screening 37 DNA repair genes in humans. Cancer Epidemiol Biomarkers Prev 11:1054-1064

5. Costa S, Pinto D, Pereira D et al (2006) DNA repair polymorphisms might contribute differentially on familial and sporadic breast cancer susceptibility: a study on a Portuguese population. Breast Cancer Res Treat 103:209-217

6. Au WW, Navasumrit P, Ruchirawat M (2004) Use of biomarkers to characterize functions of polymorphic DNA repair genotypes. Int J Hyg Environ Health 207:301-313

7. Qu T, Morii E, Oboki K et al (2005) Micronuclei in EM9 cells expressing polymorphic forms of human XRCC1. Cancer Lett 221:91-95

8. Georgakilas AG, Bennett PV, Sutherland BM (2002) High efficiency detection of bi-stranded abasic clusters in gamma-irradiated DNA by putrescine. Nucleic Acids Res 30:2800-2808

9. Sutherland BM, Bennett PV, Cintron-Torres N et al (2002) Clustered DNA damages induced in human hematopoietic cells by low doses of ionizing radiation. J Radiat Res (Tokyo) 43(Suppl):S149-S152

10. Sutherland BM, Bennett PV, Sutherland JC et al (2002) Clustered DNA damages induced by $x$ rays in human cells. Radiat Res 157:611-616

11. Ward JF (1995) Radiation mutagenesis: the initial DNA lesions responsible. Radiat Res 142:362-368

12. Goodhead DT, Thacker J, Cox R (1993) Weiss Lecture. Effects of radiations of different qualities on cells: molecular mechanisms of damage and repair. Int J Radiat Biol 63:543-556

13. Gray NK (1998) Translational control by repressor proteins binding to the 5'UTR of mRNAs. Methods Mol Biol 77:379-397

14. Henning W, Sturzbecher HW (2003) Homologous recombination and cell cycle checkpoints: Rad51 in tumour progression and therapy resistance. Toxicology 193:91-109 